\title{
Efeito da concentração de nutrientes no crescimento, produtividade e qualidade de morangos em hidroponia
}

\author{
Isabelita P Portela; Roberta MN Peil; Cesar Valmor Rombaldi \\ UFpel-FAEM, C. Postal 354, 96010-900 Pelotas-RS; isaportella@hotmail.com; rmpeil@ufpel.edu.br; cesarvrf@ufpel.edu.br
}

\begin{abstract}
RESUMO
Com o objetivo de estudar o efeito da concentração da solução nutritiva sobre o crescimento da planta, a produtividade e características químicas e fitoquímicas das frutas do morangueiro cultivar Camarosa em sistema hidropônico do tipo NFT, em Pelotas (RS), diferentes concentrações iônicas (CE) da solução foram avaliadas: 0,9; 1,5; 2,1;2,7 dS m ${ }^{-1}$, em experimento realizado de 19/05 a 04/01/2010; e 0,$7 ; 1,2 ; 1,7 ; 2,2$ e $2,7 \mathrm{dS} \mathrm{m}^{-1}$, em experimento realizado de $07 / 06$ a $04 / 01 / 2011$. Avaliaram-se a matéria fresca e seca de folhas, coroa, raízes e frutas, a área foliar, o número de frutas e o peso médio das frutas. Amostras das frutas foram analisadas em relação ao teor de sólidos solúveis totais, à acidez titulável, às concentrações de antocianinas, ácido L-ascórbico, compostos fenólicos totais e à capacidade antioxidante, no segundo experimento. Os resultados indicaram que a $\mathrm{CE}$ entre 1,2 e $1,5 \mathrm{dS} \mathrm{m}^{-1}$ favorece o crescimento da planta e a produtividade. Quando a CE diminuiu de 1,7 para $1,2 \mathrm{dS} \mathrm{m}^{-1}$, os teores de sólidos solúveis, de antocianinas e de ácido L-ascórbico diminuíram em 17, 17 e 15\%, respectivamente, e a produtividade e a concentração de compostos fenólicos totais aumentaram em 52 e $22 \%$, respectivamente. O peso médio das frutas foi reduzido com a elevação da CE no primeiro experimento e não foi afetado, assim como a acidez titulável e a capacidade antioxidante, no segundo experimento. A solução nutritiva com $\mathrm{CE}$ entre $1,2 \mathrm{e} 1,5 \mathrm{dS} \mathrm{m}^{-1}$ pode ser indicada para obter maior produtividade, sem grandes perdas na qualidade das frutas em sistema hidropônico NFT.
\end{abstract}

Palavras-chave: Fragaria $x$ ananassa, características químicas, fitoquímicos, condutividade elétrica.

\begin{abstract}
Effect of nutrient concentration on growth, yield and quality of strawberries in hydroponic system
\end{abstract}

Aiming to study the effect of the nutrient solution concentration on plant growth, yield and chemical and phytochemical characteristics of strawberry fruits of cultivar Camarosa in NFT hydroponic system in Pelotas, Rio Grande do Sul state, Brazil, different ionic concentrations (EC) of the solution were evaluated: $0.9,1.5,2.1$, $2.7 \mathrm{dS} \mathrm{m}^{-1}$, in experiment carried out from May 19, 2009 to January 4, 2010; and $0.7,1.2,1.7,2.2$, and $2.7 \mathrm{dS} \mathrm{m}^{-1}$, in experiment carried out from June 07,2010 to January 4, 2011. Fresh and dry matter of leaves, crown, roots and fruits, leaf area, number of fruits and the average fruit weight were evaluated. Fruit samples were analyzed regarding to total soluble solids content, acidity, concentrations of anthocyanins, L-ascorbic acid, total phenolic compounds and antioxidant capacity in the second experiment. The results indicated that EC from 1.2 to $1.5 \mathrm{dS} \mathrm{m}^{-1}$ promoted plant growth and fruit yield. When EC decreased from 1.7 to $1.2 \mathrm{dS} \mathrm{m}^{-1}$, soluble solids, anthocyanin and L-ascorbic acid content decreased by 17, 17 and 15\%, respectively; and fruit yield and phenolic compounds concentration were increased by 52 and $22 \%$, respectively. The average fruit weight was reduced with increasing EC in the first experiment and was not affected, as well as the acidity and the antioxidant capacity, in the second experiment. Nutrient solution from 1.2 to $1.5 \mathrm{dS} \mathrm{m}^{-1} \mathrm{EC}$ can be indicated to obtain higher yield without major losses in fruit quality in NFT hydroponic system.

Keywords: Fragaria $x$ ananassa, chemical characteristics, phytochemicals, electrical conductivity.

\section{(Recebido para publicação em 18 de abril de 2011; aceito em18 de maio de 2012) (Received on April 18, 2011; accepted on May 18, 2012)}

A cultura do morangueiro vem apresentando considerável crescimento no que se refere à área cultivada, produtividade e qualidade da fruta no Brasil, tornando-se a principal cultura no grupo das pequenas frutas (Farias et al., 1998).

No Brasil, tem crescido nos últimos anos o interesse pelos sistemas de cultivo sem solo (hidroponia e cultivo em substratos), mas ainda há poucos estudos sobre a adaptação da cultura a este tipo de sistema de produção.

Nesses sistemas de cultivo, o fornecimento de água e nutrientes pode ser melhor ajustado às necessidades da planta, reduzindo as perdas por excessos, principalmente em se tratando de sistemas fechados. Fator importante a ser destacado é a possibilidade de cultivar as plantas em bancadas ou suportes acima do nível do solo, facilitando a colheita. Os sistemas de cultivo sem solo ainda permitem aumentar a densidade das plantas e a produtividade, diminuindo os custos da lavoura (Giménez et al., 2008).

Existem diversas formulações de soluções nutritivas para o cultivo sem solo do morangueiro. Porém, as formulações podem variar para uma mesma espécie vegetal, uma vez que a absorção de nutrientes varia com a variedade cultivada, o estágio de desenvolvimento e as condições climáticas, entre outros fatores (Costa, 2004).

$\mathrm{O}$ crescimento expressa as condições morfo-fisiológicas da planta e se propõe a acompanhar a produção fotossintética, avaliada por meio do acúmulo de matéria seca (Nieuwhof et al., 1991), sendo influenciado pela quantidade e pela proporção dos nutrientes fornecidos pela solução nutritiva para morangueiro cultivado em substrato (Andriolo et al., 2009).

A composição da solução nutritiva varia de acordo com o crescimento da 
planta, e a amplitude de variação depende da relação entre o seu crescimento e o volume de solução empregado, sendo que, o crescimento das plantas não causa apenas decréscimo nas quantidades totais de íons nutrientes disponíveis para as raízes, mas também, alterações qualitativas na solução, uma vez que nem todos os elementos são absorvidos nas mesmas proporções. As mudanças na absorção de água e nutrientes, proporcionadas pela variação da condutividade elétrica do meio nutritivo, levam a alterações da fisiologia das plantas. Essas alterações relacionam-se, entre outros fatores, à abertura estomática e ao aumento ou diminuição da área foliar, estando esses fatores intimamente relacionados à eficiência fotossintética, e conseqüentemente, à produção de material seco pelas plantas (Li, 2000).

$\mathrm{O}$ efeito da concentração de nutrientes da solução nutritiva sobre o crescimento da planta, a produtividade e a qualidade das frutas é influenciado pelas condições ambientais. A concentração elevada da solução nutritiva dificulta a absorção de água pelas plantas, agravando os efeitos negativos do estresse hídrico sobre o crescimento e a produtividade, sobretudo em condições de elevada demanda evaporativa da atmosfera. Por outro lado, baixas concentrações de solução nutritiva combinadas com condições ambientais de reduzida demanda evaporativa da atmosfera diminuem tanto o teor de massa seca como a qualidade da produção (Andriolo et al., 2009).

A caracterização química das frutas é de grande importância, pois permite obter informações sobre a qualidade do produto final. O teor de sólidos solúveis totais (açúcares) e a acidez são considerados parâmetros importantes para avaliar a qualidade das frutas quanto ao sabor. Os fitoquímicos (fenóis totais, antocianinas, ácido L-ascórbico etc) são compostos provenientes do metabolismo secundário das plantas e vêm sendo amplamente estudados em frutas devido às suas propriedades funcionais benéficas à saúde (atividade antioxidante), e, em alguns casos (antocianinas), a sua relação com a coloração das frutas (Manhita et al., 2006).

Os limites de condutividade elétrica das soluções nutritivas indicados para o morangueiro em hidroponia são de 1,0 a 1,2 dS m $\mathrm{m}^{-1}$ (Moraes \& Furlani, 1999), já para o cultivo em substrato os valores são de 1,4 a 1,8 dS m-1 (Giménez et al., 2008), sendo estes considerados os mais favoráveis à produtividade e à qualidade das frutas. Os resultados da literatura mostram que tanto o crescimento e a produtividade, como a qualidade organoléptica das frutas, podem ser afetados pela concentração da solução nutritiva. $\mathrm{O}$ crescimento, a produtividade e o tamanho das frutas são aumentados com valores abaixo de $1,4 \mathrm{dS} \mathrm{m}^{-1}$, porém, o teor de açúcares é reduzido, para cultivo em substrato (Andriolo et al., 2009). Não se tem conhecimento sobre estudos que tratem conjuntamente o crescimento, a produtividade, a concentração de açúcares e dos principais compostos fitoquímicos e os relacionem com a concentração da solução nutritiva em morangueiro cultivado hidroponicamente.

Deve-se buscar trabalhar com concentrações de nutrientes que promovam crescimento e produtividades adequados, mas, ao mesmo tempo, não causem prejuízos às características organolépticas, relacionadas à concentração de açúcares e à acidez, bem como à concentração de fitoquímicos.

Trabalhos sobre formulações de soluções nutritivas têm sido realizados para vários tipos de hortaliças, como alface (Cometti et al., 2008), melão (Duarte et al., 2008), abobrinha italiana (Strassburger et al., 2011), e inclusive para o morangueiro cultivado em substrato (Andriolo et al., 2009), mas são escassas as informações sobre a composição e concentração da solução nutritiva para o morangueiro em hidroponia.

Estudou-se o efeito da concentração da solução nutritiva sobre o crescimento da planta, a produtividade e as características químicas e fitoquímicas das frutas do morangueiro cultivado em sistema hidropônico NFT.

\section{MATERIAL E MÉTODOS}

Dois experimentos foram realizados entre maio de 2009 e janeiro de 2010 e entre junho de 2010 e janeiro de 2011 , em campo experimental da Universidade Federal de Pelotas, município de Capão do Leão (RS) (31 $52^{\circ}$ S, 52 $21^{\circ}$ 'W, altitude $13 \mathrm{~m})$.

Utilizou-se estufa modelo "Arco Pampeana", disposta no sentido norte-sul, revestida com filme de polietileno de baixa densidade (150 $\mu \mathrm{m}$ de espessura). As mudas de morangueiro, cultivar Camarosa, oriundas do Chile, foram transplantadas em 19 de maio de 2009 e 07 de junho de 2010, para bancadas de cultivo com o uso da técnica NFT (Cooper, 1973). O sistema era composto por bancadas de cultivo, constituídas por telhas de fibrocimento $(3,66 \times 1,1 \mathrm{~m}$, espessura $6 \mathrm{~mm}$ ), com seis canais de 5 $\mathrm{cm}$ de profundidade), impermeabilizadas com polietileno preto, colocadas sobre cavaletes de madeira a $85 \mathrm{~cm}$ de altura mínima e com desnível de $2 \%$. Através de um conjunto moto bomba de 1/4 HP fixado a um tanque de armazenamento $(250 \mathrm{~L})$, a solução nutritiva era impulsionada para um cano de PVC (25 mm) perfurado, localizado na parte mais elevada das bancadas de cultivo. A partir desse ponto, a solução nutritiva percorria a base dos canais e no final dos mesmos era recolhida por um cano de PVC (100 mm), retornando até o tanque de armazenamento. As bancadas foram cobertas com polietileno dupla-face branco-preto (150 $\mu \mathrm{m}$ de espessura), com orifícios para colocação das mudas.

O espaçamento utilizado foi de 40 cm entre plantas nos canais de cultivo e $18 \mathrm{~cm}$ entre linhas (canais), totalizando 54 plantas por bancada, com distância lateral entre estas de $50 \mathrm{~cm}$, resultando na densidade de 9,34 plantas $\mathrm{m}^{-2}$.

A solução nutritiva recomendada por Sonneveld \& Straver (1994) foi empregada como solução base, com concentração de macronutrientes (em mmol L-1) de 10,00 de $\mathrm{NO}_{3}^{-} ; 1,26 \mathrm{de}$ $\mathrm{H}_{2} \mathrm{PO}_{4}^{-} ; 1,08$ de $\mathrm{SO}_{4}^{2-} ; 0,50$ de $\mathrm{NH}_{4}^{+}$; 5,24 de $\mathrm{K}^{+} ; 2,74$ de $\mathrm{Ca}^{2+}$; 1,10 de $\mathrm{Mg}^{2+}$; e de micronutrientes (em mg L $\mathrm{m}^{-1}$ ) de 1,00 de Fe; 0,60 de Mn; 0,05 de Zn; 0,30 de B; 0,05 de $\mathrm{Cu}$; 0,05 de Mo. A condutividade elétrica (CE) foi de $1,5 \mathrm{dS} \mathrm{m}^{-1}$. Para o preparo das soluções nutritivas utilizou-se água da chuva $\left(\mathrm{CE}=0,0 \mathrm{dSm}^{-1}\right)$ previamente recolhida em um tanque de armazenamento de 5000 litros.

O fator experimental estudado foi a 
concentração iônica da solução nutritiva. Os tratamentos foram constituídos por concentrações múltiplas dos macronutrientes da solução nutritiva descrita anteriormente, de forma a serem obtidos valores de $\mathrm{CE}$ de 0,$9 ; 1,5 ; 2,1 ; 2,7$ e $3,3 \mathrm{dSm}^{-1}$, no experimento realizado em 2009. Devido à morte de todas as plantas do tratamento de CE de 3,3 dS $\mathrm{m}^{-1}$, no meio do período experimental do ano de 2009, optou-se por modificar os valores de $\mathrm{CE}$ constituintes dos tratamentos para 0,$7 ; 1,2 ; 1,7 ; 2,2$ e $2,7 \mathrm{dS}$ $\mathrm{m}^{-1}$ no segundo experimento, realizado em 2010. Os micronutrientes foram mantidos na concentração original em todos os tratamentos.

As soluções foram monitoradas diariamente através da medida da condutividade elétrica (empregando-se um eletrocondutivímetro digital) e do $\mathrm{pH}$ (empregando-se um pHmetro digital). $\mathrm{O}$ pH foi mantido entre 5,5 e 6,5, através da adição de solução de correção à base de hidróxido de potássio $(\mathrm{KOH}$ $1 \mathrm{~N})$ ou ácido sulfúrico $\left(\mathrm{H}_{2} \mathrm{SO}_{4} 1 \mathrm{~N}\right)$. A reposição de nutrientes ou de água foi realizada através da adição de solução estoque concentrada ou de água, quando a condutividade elétrica sofria, respectivamente, uma diminuição ou um aumento da ordem de $10 \%$.

A circulação da solução nutritiva era intermitente, programada por um temporizador, que era acionado a partir das $8 \mathrm{~h}$ da manhã até as $18 \mathrm{~h}$ durante 15 minutos, com intervalos entre circulações de 45 minutos, durante todo o ciclo de cultivo.

As colheitas iniciaram-se em 08/09/09 e 15/08/10. Com a finalidade de avaliar o crescimento e a produtividade da cultura, ao final dos experimentos (04/01/10 e 04/01/11), as plantas foram separadas em quatro frações: folhas, coroa, raízes e frutas, as quais foram pesadas para a obtenção da massa fresca. As diferentes frações das plantas foram secas em estufa de ventilação forçada a $65^{\circ} \mathrm{C}$, até peso constante e depois pesadas em balança de precisão e, assim, determinada a massa seca. Também foi avaliada a área foliar ao final dos experimentos, através de um equipamento medidor de imagens (LI-COR, modelo 3100). As frutas colhidas durante o processo produtivo e as folhas provenientes de desfolhas antecipadas também foram avaliadas e incorporadas às frações correspondentes.

As análises referentes às características químicas das frutas foram realizadas somente no segundo experimento (ano de 2010). Uma amostra de $100 \mathrm{~g}$ de frutas completamente maduras por repetição (excetuando-se para o tratamento

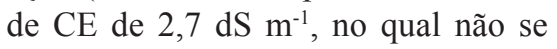
obteve quantidade de frutas suficiente para compor as amostras) foi coletada pela manhã do dia 26/11/10 e encaminhada ao Laboratório de Pós-Colheita da UFPel. Analisaram-se o teor de sólidos solúveis totais, com um refratômetro manual, e a acidez titulável, utilizando-se 10 mL de suco diluídos em 90 mL de água destilada, cuja diluição foi titulada com solução de hidróxido de sódio $0,1 \mathrm{~N}$ até pH 8,1. Também, analisou-se o teor de antocianinas (Lees \& Francis, 1972); de compostos fenólicos totais (Folin-Ciocalteu; Wettasinghe \& Shahidi, 1999); de ácido L-ascórbico (Vinci et al., 1995); e a capacidade antioxidante (Re et al., 1999).

A radiação solar global incidente no exterior da estufa foi obtida através dos dados coletados na Estação Agroclimatológica de Pelotas, localizada a aproximadamente $450 \mathrm{~m}$ do local do experimento.

Durante os experimentos, sempre que as condições climáticas permitiram, a estufa foi mantida com as cortinas laterais e as portas frontais abertas durante a maior parte do período diurno, a fim de facilitar a entrada de insetos polinizadores. No segundo experimento (ano de 2010) foi instalada uma caixa de abelhas do tipo Jataí (Tetragonisca angustula, pertencente a família Apidae e subtribo Meliponina).

$\mathrm{O}$ delineamento experimental utilizado foi em blocos completos casualizados com quatro repetições. Cada parcela foi constituída por 13 plantas. Os dados obtidos foram submetidos à análise de variância (separadamente para cada experimento) e decomposição em componentes polinomiais, interpretando-se os resultados por meio da análise de regressão a um nível de 5\% de significância, sendo obtida a equação estimada. Para as variáveis concentração de compostos fenólicos totais, antocianinas, acido L-ascórbico e capacidade antioxidante, as comparações entre os tratamentos foram estabelecidas através do teste de Tukey $(\mathrm{p} \leq 0,05)$ de comparação de médias.

\section{RESULTADOS E DISCUSSÃO}

Os modelos matemáticos que expressam o comportamento das variáveis com diferenças significativas e submetidas à análise de regressão polinomial, e os respectivos coeficientes de determinação, são apresentados na Tabela 1 .

A produção de matéria seca dos órgãos vegetativos aéreos e das frutas aumentou com o aumento da concentração da solução nutritiva até 1,5 e 1,2 dS $\mathrm{m}^{-1}$, em 2009 e 2010, respectivamente, diminuindo com os incrementos continuados desta. Assim, ambas variáveis seguiram tendência quadrática nos dois experimentos avaliados (Figuras 1a e 1b). Os valores mais elevados de matéria seca vegetativa aérea foram observados em 2009 na CE de $1,5 \mathrm{dS} \mathrm{m}^{-1}(22,99 \mathrm{~g}$ planta $\left.^{-1}\right)$, com redução de $81 \%$ na $\mathrm{CE}$ de 2,7 dS m ${ }^{-1}$; e, em 2010, na CE de 1,2 $\mathrm{dS} \mathrm{m} \mathrm{m}^{-1}\left(52,57 \mathrm{~g} \mathrm{planta}^{-1}\right)$, com redução de $85 \%$ na CE de $2,7 \mathrm{dS} \mathrm{m}^{-1}$. Comportamento semelhante foi observado na produção de matéria seca das frutas. Os valores mais elevados também foram observados em 2009 na CE de 1,5 dS $\mathrm{m}^{-1}$ (26,23 g planta $\left.^{-1}\right)$, com redução de $85 \%$ na CE de $2,7 \mathrm{dS} \mathrm{m}^{-1}$; e, em 2010 , na CE de 1,2 $\mathrm{dS} \mathrm{m}^{-1}\left(56,44 \mathrm{~g}\right.$ planta $\left.^{-1}\right)$, com redução de $92 \%$ na $\mathrm{CE}$ de $2,7 \mathrm{dS}$ $\mathrm{m}^{-1}$. No experimento realizado em 2009 , a produção de matéria seca de raízes não foi afetada significativamente pela CE, com valor médio de 4,62 g planta $^{-1}$. Porém, no ano de 2010, a produção de matéria seca das raízes seguiu tendência quadrática (Figura 1b), com maior valor na CE de 1,2 $\mathrm{dS} \mathrm{m}^{-1}$ (10,03 g planta $\left.^{-1}\right)$.

As relações de partição de matéria seca, raízes/planta, vegetativo aéreo/ planta e frutas/planta, não sofreram influência significativa dos tratamentos no ano de 2009, com médias de 15,7\%, $42,4 \%$ e $41,9 \%$, respectivamente. Entretanto, no ano de 2010, observou-se comportamento quadrático para as três relações de partição (Figura 1c). $\mathrm{O}$ aumento da CE entre 0,7 e $1,7 \mathrm{dS} \mathrm{m}^{-1}$ elevou a distribuição de matéria seca para as frutas, com valor máximo de $60,0 \%$, reduzindo a partição para a parte aérea 

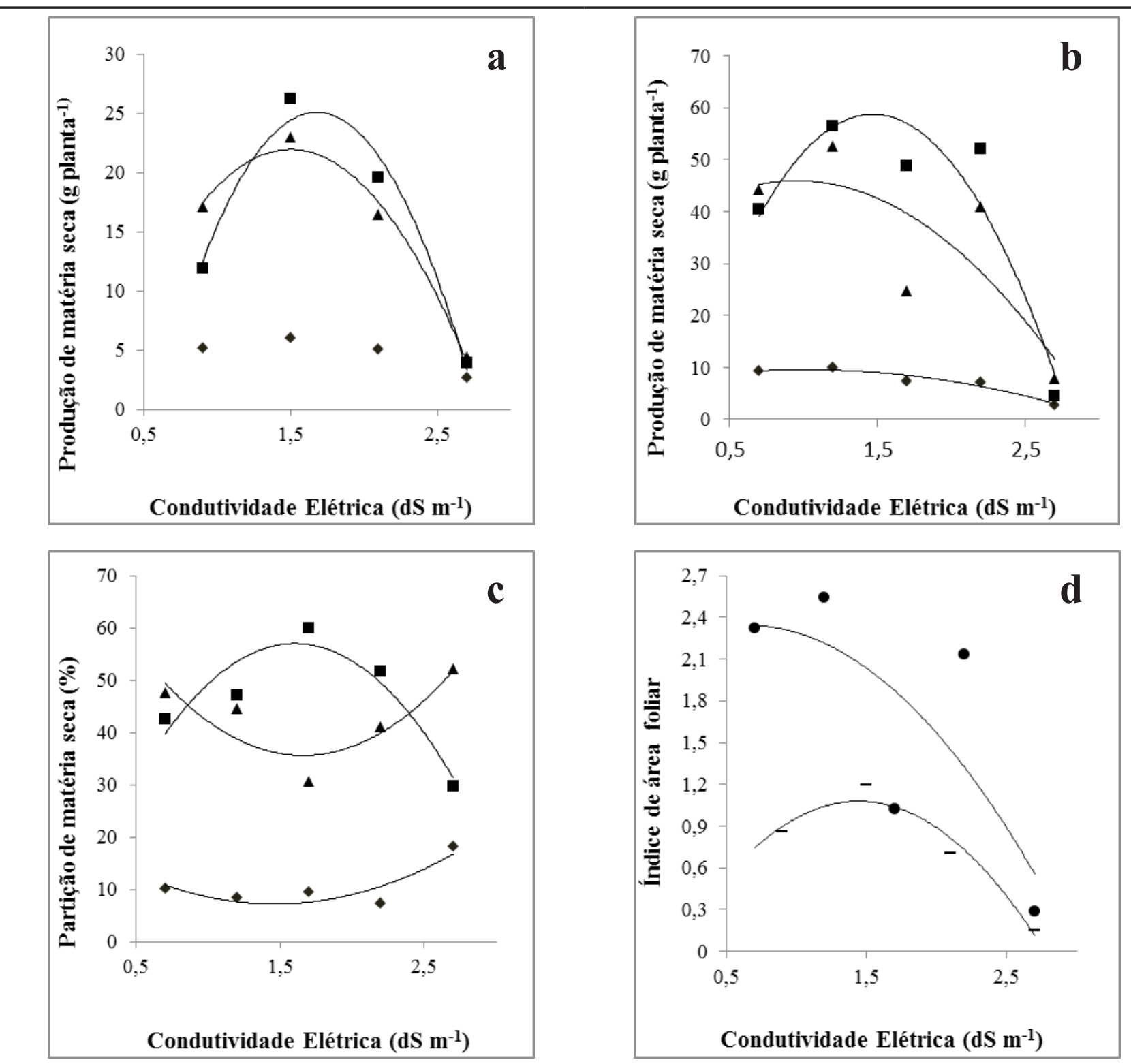

\section{$\bullet$ Raízes $\boldsymbol{\bullet}$ Frutas $\Delta$ PA Vegetativa}

Figura 1. Produção (a, b), partição de matéria seca (c) e índice de área foliar (d) de morangueiro em sistema hidropônico em função de diferentes concentrações iônicas da solução nutritiva (expressas através da condutividade elétrica) em dois anos de cultivo: 2009 (a, d) e 2010 (b, c, d) [Dry matter production (a, b), partitioning (c) and leaf area index (d) of strawberry crop in hydroponic system under different ionic concentrations of the nutrient solution (expressed by the electrical conductivity) in two crop years: 2009 (a, d) and 2010 (b, c, d)]. Pelotas, 2009 e 2010.

vegetativa (30,5\%). A elevação da $\mathrm{CE}$ acima de $1,7 \mathrm{dS} \mathrm{m} \mathrm{m}^{-1}$ ocasionou o inverso, havendo uma redução da ordem de $50 \%$ na contribuição da matéria seca das frutas $(29,8 \%)$ para o total da planta na CE de $2,7 \mathrm{dS} \mathrm{m}^{-1}$, e elevação da contribuição da parte aérea vegetativa $(52,0 \%)$ e das raízes (18,2\%). A área foliar foi drasticamente reduzida com o aumento da CE (Figura 1d), seguindo tendência quadrática em ambos os experimentos, com os maiores valores na $\mathrm{CE}$ de $1,5 \mathrm{dS}$ $\mathrm{m}^{-1}\left(1,19 \mathrm{~m}^{2} \mathrm{~m}^{-2}\right)$ em 2009, e na CE de $1,2 \mathrm{dS} \mathrm{m}^{-1}\left(2,54 \mathrm{~m}^{2} \mathrm{~m}^{-2}\right)$ em 2010.

No ano de 2009 (Figura 2a), maior número de frutas colhidas e produtividade foram obtidos na CE de $1,5 \mathrm{dS} \mathrm{m}^{-1}$ (32,5 e 249,7 $\mathrm{g} \mathrm{planta}^{-1}$, correspondendo a $2,3 \mathrm{~kg} \mathrm{~m}^{-2}$ ), havendo redução de $80 \%$ no número de frutas e de $87 \%$ na produtividade na CE de $2,7 \mathrm{dS} \mathrm{m}^{-1}$, e de $55 \%$ no número de frutas e de $54 \%$ na produtividade na $\mathrm{CE}$ de $0,9 \mathrm{dS} \mathrm{m}^{-1}$. Em 2010 (Figura 2b), a maior produtividade foi obtida na CE de 1,2 $\mathrm{dS} \mathrm{m}^{-1}(608,2 \mathrm{~g}$ planta $^{-1}$, correspondendo a $\left.5,7 \mathrm{~kg} \mathrm{~m}^{-2}\right)$, com redução de $94 \%$ na CE de 2,7 dS $\mathrm{m}^{-1}$, e o maior número de frutas foi obtido na CE de $2,2 \mathrm{dS} \mathrm{m}^{-1}(58,1)$, com redução de $92 \%$ na $\mathrm{CE}$ de $2,7 \mathrm{dS} \mathrm{m}^{-1}$. O peso médio das frutas também diminuiu com o aumento da concentração da solução nutritiva, seguindo tendência 


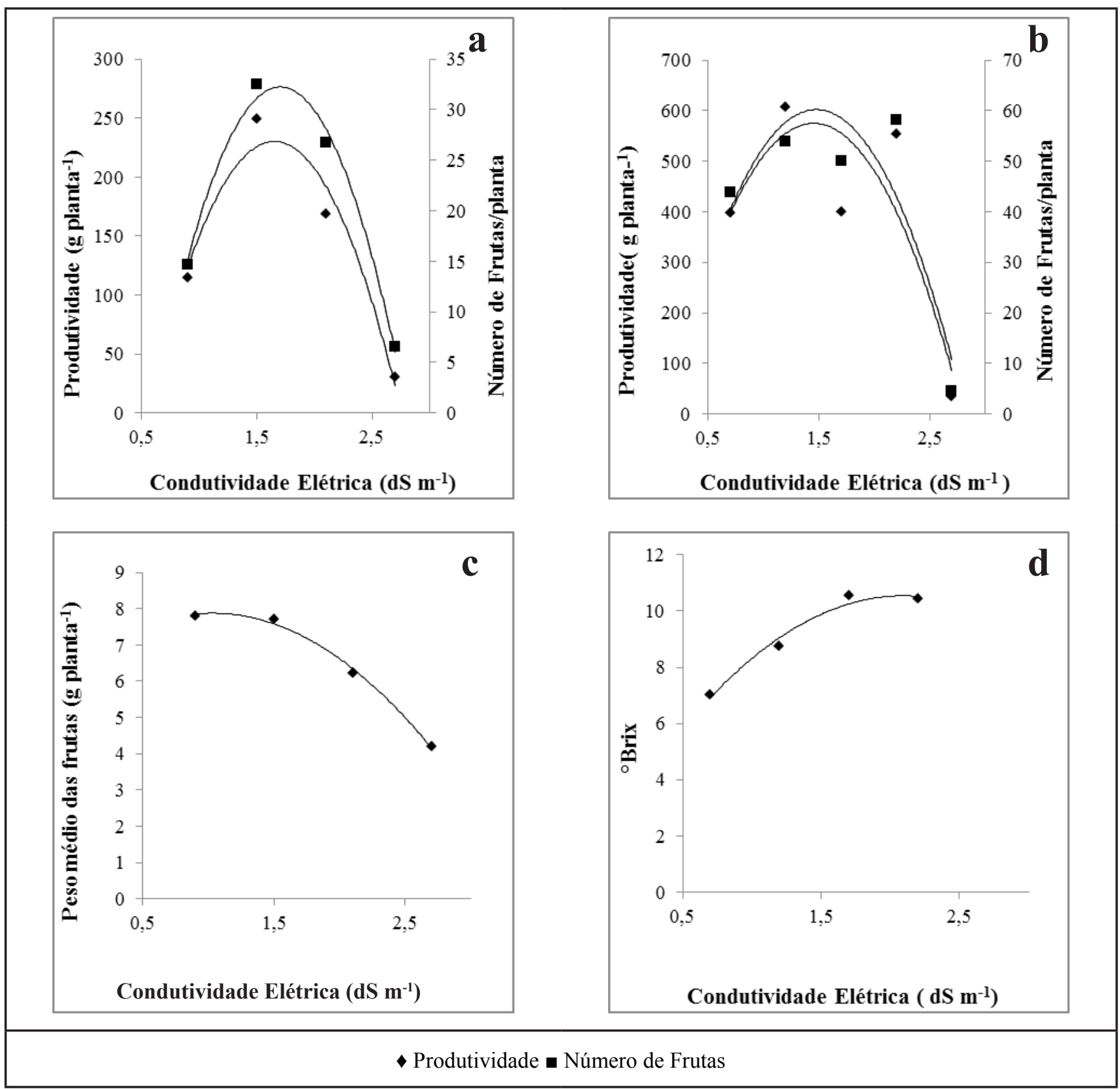

Figura 2: Produtividade (a, b), peso médio (c) e teor de sólidos solúveis totais ( ${ }^{\circ}$ Brix) (d) de frutas de morangueiro cultivado em sistema hidropônico em função de diferentes concentrações iônicas da solução nutritiva (expressas através da condutividade elétrica) em dois anos de cultivo: 2009 (a, c) e 2010 (b, d). [Yield (a, b), average weight (c) and total soluble solids content ( ${ }^{\circ}$ Brix) (d) of strawberries fruits in hydroponic system under different ionic concentrations of the nutrient solution (expressed by the electrical conductivity). in two crop years: 2009 (a,c) and 2010 (b,d)]. Pelotas, UFPel, 2009/2010.

quadrática em 2009 (Figura 2c), com redução de $46 \%$ do tratamento de $\mathrm{CE}$ de 1,5 para o de $\mathrm{CE}$ de $2,7 \mathrm{dS} \mathrm{m}^{-1}$. Porém, em 2010, o tamanho das frutas não foi afetado, com média de $8,7 \mathrm{~g}$ fruta $^{-1}$. Entretanto, a qualidade das frutas foi beneficiada com a elevação da concentração da solução em 2010. O teor de sólidos solúveis (analisado somente em 2010, Figura 2d) aumentou em $66 \%$, passando de 7,0 a $10,6{ }^{\circ}$ Brix com a elevação da
CE de 0,7 para $1,7 \mathrm{dS} \mathrm{m}^{-1}$, não havendo aumento deste valor na CE de $2,2 \mathrm{dS} \mathrm{m}^{-1}$. A acidez titulável não sofreu influência significativa da $\mathrm{CE}$, com valor médio de 0,96\% de ácido cítrico.

O índice de colheita, que representa a eficiência de conversão de produtos sintetizados em material de importância econômica (dado pela relação matéria fresca de frutas/matéria fresca do total da planta), em ambos os experimentos, não foi influenciado pelas concentrações, com médias de 0,55 em 2009 e $0,62 \mathrm{em} 2010$.

A análise dos compostos fitoquímicos (Tabela 2) indicou que a elevação da concentração da solução nutritiva de 1,2 para $1,7 \mathrm{dS} \mathrm{m}^{-1}$ aumentou o teor de antocianinas e de ácido L-ascórbico nas frutas e diminuiu a concentração de compostos fenólicos totais. Porém, a capacidade antioxidante não foi afetada 
Tabela 1. Equações de regressão e seus respectivos coeficientes de determinação $\left(\mathrm{R}^{2}\right)$, relacionando as variáveis avaliadas (y) com a condutividade elétrica (CE) da solução nutritiva para o morangueiro cultivar Camarosa em sistema hidropônico, em dois anos de cultivo [regression equations and their coefficient of determination $\left(\mathrm{R}^{2}\right)$ linking evaluated variables $(\mathrm{y})$ to electrical conductivity (EC) of the nutrient solution for strawberry crop cultivar Camarosa in hydroponic system, in two crop years]. Pelotas, UFPel, 2009/2010.

\begin{tabular}{|c|c|c|c|c|}
\hline \multirow{2}{*}{ Variável } & \multicolumn{2}{|l|}{2009} & \multicolumn{2}{|l|}{2010} \\
\hline & Fórmula & $\mathbf{R}^{2}$ & Fórmula & $\mathbf{R}^{2}$ \\
\hline Matéria seca vegetativa & $Y=-12,42 x^{2}+37,26 x-5,99$ & 0,98 & $Y=11,25 x^{2}+21,40 X+35,79$ & 0,64 \\
\hline Massa seca frutas & $Y=-20,18 x^{2}+69,83 x-33,47$ & 0,97 & $Y=-33,09 x^{2}+97,25 x-12,69$ & 0,88 \\
\hline Massa seca raízes & $\mathrm{ns}^{1}$ & & $Y=-2,27 x^{2}+4,59 x+7,24$ & 0,92 \\
\hline Relação de massa seca (vegetativo/planta) & ns & & $Y=14,99 x^{2}-49,77 x+6,93$ & 0,75 \\
\hline Relação de massa seca (frutas/planta) & ns & & $Y=-22,22 x^{2}+68,01+2,54$ & 0,86 \\
\hline Relação de massa seca (raízes/planta) & ns & & $Y=6,23 x^{2}-18,23 x+20,53$ & 0,75 \\
\hline Produtividade & $Y=-189,35 x^{2}+626,1 x-287,39$ & 0,94 & $Y=-314,17 x^{2}+911,83 x-86,61$ & 0,73 \\
\hline Número de frutas & $Y=-26,47 x^{2}+90,30 x-44,75$ & 0,98 & $Y=-32,97 x^{2}+97,27 x-11,53$ & 0,80 \\
\hline Peso médio das frutas & $Y=-1,33 x^{2}+2,74 x+6,46$ & 0,99 & ns & \\
\hline Teor de sólidos solúveis ( $\left.{ }^{\circ} \mathrm{Brix}\right)$ & Não avaliado & & $Y=1,86 x^{2}+7,79 x+2,37$ & 0,97 \\
\hline Índice de área foliar & $Y=-0,61 x^{2}+1,76 x-0,19$ & 0,94 & $Y=-0,42 x^{2}+0,55 x+2,16$ & 0,58 \\
\hline
\end{tabular}

${ }^{1}$ ns: não significativo - análise de variância não significativa.

pela variação da CE.

Os menores crescimentos (Figura 1) e produtividade (Figura 2) obtidos no ano de 2009 se devem às condições de baixa luminosidade e grande precipitação pluviométrica reinantes durante o mês de novembro (quando ocorre a maior concentração da frutificação da cultivar Camarosa na região), o que prejudicou a atividade dos insetos polinizadores e o crescimento das frutas. Neste ano, a radiação solar acumulada em novembro foi de 406,7 $\mathrm{MJ} \mathrm{m}^{-2}$, com média diária de $13,6 \mathrm{MJ} \mathrm{m}^{-2}$, enquanto que no mesmo período de 2010, o acumulado foi de $616,6 \mathrm{MJ} \mathrm{m}^{-2}$, com média diária de $20,6 \mathrm{MJ} \mathrm{m}^{-2}$. Adicionalmente, no ano de 2010 instalou-se uma caixa de abelhas no interior da estufa, a fim de facilitar a polinização. O maior valor de produtividade observado em 2009 foi de $250 \mathrm{~g}$ planta $^{-1}$ e, em 2010, foi de 608 g planta $^{-1}$.

Apesar dos valores notadamente superiores das variáveis relacionadas ao crescimento (Figura 1a, 1b e 1d) e à produtividade (Figura 2a e 2b) no ano agrícola de 2010, pode-se observar resposta semelhante entre os dois cultivos em função da variação da $\mathrm{CE}$ para a maioria destas. A elevação inicial do valor da CE levou a um aumento do crescimento dos órgãos vegetativos e reprodutivos e da produtividade da cultura até o valor de 1,5 (2009) e $1,2 \mathrm{dS} \mathrm{m}^{-1}$ (2010), sendo que os incrementos posteriores da concentração da solução ocasionaram efeitos negativos para a maioria das variáveis, diminuindo a alocação de fotoassimilados para as frutas, em 2010 (Figura 1c), e chegando a patamares de crescimento quase incompatíveis com o funcionamento vegetal na $\mathrm{CE}$ de 2,7 dS $\mathrm{m}^{-1} \mathrm{e}$ levando à morte das plantas na $\mathrm{CE}$ de $3,3 \mathrm{dS} \mathrm{m}^{-1}$ (no experimento realizado em 2009).

$\mathrm{O}$ efeito da CE sobre o crescimento e a produtividade da cultura deve ser abordado desde dois pontos de vista. Por um lado, valores baixos de CE podem indicar uma concentração abaixo da faixa considerada ótima para o crescimento (Grattan \& Grieve, 1999), o que diminuiu, consequentemente, a produtividade da cultura, como observado nesta pesquisa e anteriormente por Andriolo et al. (2002) para morangueiro em substrato. Por outro lado, a concentração de sais do meio radicular, além de condicionar a absorção de nutrientes essenciais, influencia também a absorção de água para o crescimento das plantas. Soluções nutritivas muito concentradas provocam em um primeiro momento, a inibição da absorção de água, induzindo a planta a um estresse hídrico e, após, até a própria absorção mineral é inibida (Grattan \& Grieve, 1999). Os resultados obtidos indicam que o efeito mais pronunciado do aumento da concentração iônica do meio radicular, no que se refere aos fatores determinantes do crescimento, ocorreu sobre a expansão das folhas, pois houve uma redução drástica da área foliar com o aumento da CE (levando à redução da produção de matéria seca, do número de frutas e da produtividade), confirmando os resultados descritos na literatura (Andriolo et al., 2009).

Em ambos experimentos houve coincidência entre as concentrações de nutrientes em que se obtiveram o maior crescimento vegetativo da cultura e a maior produtividade: 1,5 (2009) e 1,2 $\mathrm{dS} \mathrm{m}^{-1}$ (2010); de forma semelhante ao observado por Andriolo et al. (2002) em cultivo em substrato. Entretanto, em trabalho realizado por Andriolo et al. (2009), o maior crescimento foi observado com valor de CE de 1,4 $\mathrm{dS} \mathrm{m}^{-1}$, enquanto a maior produtividade ocorreu para a CE de $0,9 \mathrm{dS} \mathrm{m}^{-1}$, também em cultivo em substrato. Devido às baixas interações existentes entre os nutrientes minerais em sistemas hidropônicos (diferentemente do que freqüentemente ocorre em substratos), dificilmente são observados efeitos negativos da maior disponibilidade de nutrientes - para valores de CE que não causem interferência na absorção hídrica e mineral - no crescimento reprodutivo das plantas.

Com base nos resultados obtidos e seguindo os critérios descritos por Shannon \& Grieve (1999), em sua classificação de hortaliças quanto à tolerância à salinidade, apesar do morangueiro não constar desta classificação, pode-se afirmar 
Tabela 2. Antocianinas totais (mg $\left.100 \mathrm{~g}^{-1} \mathrm{MF}\right)^{1}$, L- ácido L-ascórbico (mg $\left.100 \mathrm{~g}^{-1} \mathrm{MF}\right)^{2}$, compostos fenólicos totais (mg $\left.100 \mathrm{~g}^{-1} \mathrm{MF}\right)^{3}$ e capacidade antioxidante (TEAC) $)^{4}$ da cultivar de morangueiro Camarosa cultivada em sistema hidropônico em função de diferentes concentrações iônicas da solução nutritiva (anthocyanins, L-ascorbic acid, total phenolic compounds and antioxidant capacity of Camarosa strawberry crop hydroponically grown under different ionic concentrations of the nutrient solution). Pelotas, UFPel, 2010.

\begin{tabular}{lcccc}
\hline CE $\left(\mathbf{d S ~ ~ m ^ { - 1 } )}\right.$ & Antocianinas & $\begin{array}{c}\text { Ácido } \\
\text { L-ascórbico }\end{array}$ & $\begin{array}{c}\text { Fenóis } \\
\text { totais }\end{array}$ & $\begin{array}{c}\text { Capacidade } \\
\text { antioxidante }\end{array}$ \\
\hline 0,7 & $22,49 \mathrm{~b}^{5}$ & $35,54 \mathrm{~b}$ & $865,05 \mathrm{a}$ & $2,90 \mathrm{a}$ \\
1,2 & $24,59 \mathrm{~b}$ & $34,33 \mathrm{~b}$ & $876,13 \mathrm{a}$ & $3,01 \mathrm{a}$ \\
1,7 & $29,56 \mathrm{a}$ & $40,19 \mathrm{a}$ & $689,87 \mathrm{~b}$ & $3,11 \mathrm{a}$ \\
2,2 & $30,36 \mathrm{a}$ & $39,54 \mathrm{a}$ & $678,45 \mathrm{~b}$ & $3,24 \mathrm{a}$ \\
\hline $\mathrm{CV}(\%)$ & 6,93 & 9,23 & 8,93 & 7,86 \\
\hline
\end{tabular}

${ }^{1}$ Expresso em mg de cianidina-3-glucosideo por $100 \mathrm{~g}$ de matéria fresca de frutas (mg of cianidina-3glucosideo in $100 \mathrm{~g}$ of fruits fresh matter); ${ }^{2}$ Expresso em mg de ácido ascórbico por $100 \mathrm{~g}$ de matéria fresca de frutas ( $\mathrm{mg}$ of ascorbic acid in $100 \mathrm{~g}$ of fruits fresh matter); ${ }^{3}$ Expresso em mg equivalentes de ácido gálico por $100 \mathrm{~g}$ de matéria fresca de frutas (equivalent $\mathrm{mg}$ of galic acid in $100 \mathrm{~g}$ of fruits fresh matter); ${ }^{4}$ Capacidade antioxidante equivalente trolox (antioxidant capacity equivalent trolox); ${ }^{5}$ Médias seguidas pelas mesmas letras na coluna não diferem significativamente pelo teste de Tukey a 5\% (means followed by same letter in the row are not different, Tukey $5 \%$ ).

que a planta é sensível à salinidade, conforme constatado por Andriolo et al. (2009), uma vez que se observaram limites para a CE de 1,2 e $1,5 \mathrm{dS} \mathrm{m}^{-1}$, a partir dos quais houve redução estimada da produtividade em $58 \%$ e $28 \%$ para cada unidade de elevação da CE, respectivamente em 2009 e 2010.

Os resultados obtidos indicam que valores de CE entre 1,2 e $1,5 \mathrm{dS} \mathrm{m}^{-1}$ podem ser empregados para aumentar a produtividade, coincidindo com o limite máximo de $1,2 \mathrm{dS} \mathrm{m}^{-1}$ indicado por Moraes \& Furlani (1999) para morangueiro em hidroponia. Entretanto, é superior ao valor de $1,0 \mathrm{dS} \mathrm{m}^{-1}$ indicado por Andriolo et al. (2009) para cultivo em substrato em sistema fechado. Em hidroponia é possível a utilização de soluções mais concentradas do que no cultivo em substrato, uma vez que se elimina a interação substrato/solução, que é um dos fatores que leva à elevação da salinidade do meio radicular.

$\mathrm{O}$ valor médio obtido para o teor de sólidos solúveis totais das frutas $\left(9,2^{\circ}\right.$ Brix) foi superior aos 4,8 e $6,2^{\circ}$ Brix obtidos por Andriolo et al. (2009) em cultivo em substrato, aos $7,6^{\circ}$ Brix constatado por Antunes et al. (2010) e entre 4,4 e 6, $0^{\circ}$ Brix por Resende et al. (2010) em cultivos no solo. Assim, pode-se dizer que o cultivo hidropônico não reduz a concentração de açúcares das frutas, como muitas vezes propagado. A concentração de açúcares aumentou gradativamente de 7,0 até o valor máximo de $10,6^{\circ}$ Brix, obtido na CE de 1,7 $\mathrm{dS} \mathrm{m}{ }^{-1}$ (Figura 2c). Em estudos anteriores em sistemas de cultivo sem solo também foram obtidos morangos mais "doces" com valores mais altos de CE (Sarooshi \& Cresswell, 1994; Andriolo et al. 2009), sendo esta uma alternativa de manejo interessante para melhorar a qualidade organoléptica das frutas.

As concentrações de antocianinas e de ácido L-ascórbico também foram beneficiadas com o aumento da CE (Tabela 2). As concentrações de antocianinas obtidas (entre 22,5 e 30,4 mg $100 \mathrm{~g}^{-1}$ ) são inferiores ao resultado de Bordignon Júnior (2008) em cultivo no solo, de

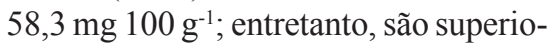
res ao de Severo et al. (2007) de 12,5 mg $100 \mathrm{~g}^{-1}$, também em cultivo no solo. A síntese de antocianinas está diretamente relacionada à incidência de luz, equilíbrio nutricional (suprimento adequado de K), mudanças de temperatura durante o crescimento e amadurecimento, e ao próprio sistema de cultivo, tendo-se estabelecido que práticas agronômicas que aumentam o crescimento vegetativo resultam em decréscimo da síntese de antocianinas (Severo et al., 2010). Os resultados obtidos no presente trabalho corroboram estas afirmativas, uma vez que as $\mathrm{CE}$ de 0,7 e $1,2 \mathrm{dS} \mathrm{m}^{-1}$, nas quais a disponibilidade de $\mathrm{K}$ era menor, induziram a um maior crescimento vegetativo das plantas (Figuras 1b, 1d) e, ao mesmo tempo, reduziram o acúmulo de antocianinas (Tabela 2). O teor máximo de ácido L-ascórbico observado na $\mathrm{CE}$

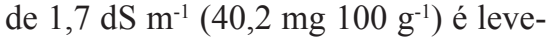
mente inferior ao observado por Martins (2010) para a cultivar Camarosa, de $44,3 \mathrm{mg} 100 \mathrm{~g}^{-1}$, em cultivo no solo. O teor de ácido L-ascórbico das frutas é influenciado pela cultivar, ponto de colheita e maturação, técnicas de análise e condições ambientais (Amaro, 2005) e, como constatado na presente pesquisa, é aumentado pela elevação da CE da solução nutritiva.

Por outro lado, a concentração de compostos fenólicos totais foi beneficiada com a diminuição da CE para valores inferiores a $1,7 \mathrm{dS} \mathrm{m}^{-1}$ (Tabela 2). Os valores obtidos, entre 678,5 e

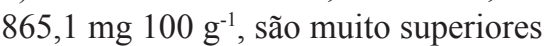
aos observados nos estudos feitos por Severo et al. (2007) e por Bordignon Júnior (2008), respectivamente, 90,9 e $171,0 \mathrm{mg} 100 \mathrm{~g}^{-1}$, em cultivos no solo. Os compostos fenólicos são sintetizados em resposta a fatores abióticos (temperatura, UV, luz e sombra), aumentando em condições de estresse. A elevação da síntese de fenóis das frutas nas $\mathrm{CE}$ de 0,7 e $1,2 \mathrm{dS} \mathrm{m}^{-1}$ pode ser uma resposta das plantas às condições de maior auto-sombreamento e sombreamento mútuo, oriundos da maior área foliar observada nessas plantas (Figura 1d).

$O$ fato de haver significativas diferenças para os teores de antocianinas, de ácido L-ascórbico e de compostos fenólicos totais, entre os trabalhos citados, é normal, tendo em vista que tratam-se de cultivares, sistemas de cultivo e condições climáticas diversas. Esses compostos são produtos do metabolismo secundário e, por conseguinte, altamente variáveis em função de estresses bióticos e abióticos, assim como das condições de cultivo (Barsan et al., 2010; Cogo et al., 2011).

$\mathrm{O}$ uso de soluções nutritivas com condutividades elétricas entre $1,2 \mathrm{e}$ $1,5 \mathrm{dS} \mathrm{m}^{-1}$ beneficiaram o crescimento (Figura 1) e a produtividade da cultura (Figura 2a, 2b), bem como a produção de compostos fenólicos totais (Tabela 2), 
porém o teor de sólidos solúveis (Figura 2d), de antocianinas e de ácido L-ascórbico (Tabela 2) foram favorecidos com o emprego da solução nutritiva de CE de $1,7 \mathrm{dS} \mathrm{m}^{-1}$, em 2010. Enquanto os teores de sólidos solúveis, de antocianinas e de ácido L-ascórbico diminuíram em 17, 17 e $15 \%$, respectivamente, a produtividade foi aumentada em $52 \%$ e a concentração de compostos fenólicos totais em $22 \%$, quando a $\mathrm{CE}$ foi reduzida de 1,7 para $1,2 \mathrm{dS} \mathrm{m}^{-1}$. Já o peso médio das frutas, característica determinante para a cotação do produto no mercado, foi reduzido com a elevação da CE em 2009 e não foi afetado em 2010, assim como a acidez titulável e a capacidade antioxidante (Tabela 2). Com base nestas observações, conclui-se que as perdas na qualidade do produto são de menor magnitude que os ganhos originados na produtividade com a redução da $\mathrm{CE}$ de 1,7 para 1,2 $\mathrm{dS} \mathrm{m}^{-1}$. Além disso, deve-se considerar a economia de fertilizantes gerada. Porém, do ponto de vista biológico, estabelece-se uma relação inversa entre o aumento da produtividade e a qualidade funcional do alimento.

Assim, pode-se concluir que a $\mathrm{CE}$ na faixa entre 1,2 e 1,5 dS m $\mathrm{m}^{-1}$ favorece o crescimento da planta e a produtividade das frutas de morangueiro em sistema hidropônico do tipo NFT. O crescimento e a produtividade diminuem quando a CE encontra-se abaixo ou acima destes valores no intervalo entre 0,7 e $2,7 \mathrm{dS}$ $\mathrm{m}^{-1}$. Os teores de sólidos solúveis totais, de antocianinas e de ácido L-ascórbico das frutas são aumentados com a elevação da $\mathrm{CE}$ para $1,7 \mathrm{dS} \mathrm{m}^{-1}$. A concentração de compostos fenólicos totais é aumentada com a redução da CE para $1,2 \mathrm{dS} \mathrm{m}^{-1}$. A solução nutritiva com $\mathrm{CE}$ na faixa entre 1,2 e $1,5 \mathrm{dS} \mathrm{m}^{-1}$ pode ser indicada para obter maior produtividade, sem grandes perdas na qualidade das frutas nesse sistema de cultivo.

\section{AGRADECIMENTOS}

Os autores agradecem ao CNPq, à CAPES e à FAPERGS o auxílio financeiro.

\section{REFERÊNCIAS}

AMARO FS. 2005. Teores de licopeno e ácido ascórbico em morangos cv. Vila Nova produzidos em sistemas de cultivo orgânico e convencional. Porto Alegre: UFRGS.120p. (Dissertação mestrado).

ANDRIOLO JL; BONINI JV; BOEMO MP. 2002. Acumulação de matéria seca em frutos de morangueiro cultivados em substrato com diferentes soluções nutritivas. Horticultura Brasileira 20: 24-27.

ANDRIOLO JL; JANISCH DI; SHIMITT OJ; VAZ MAB; CARDOSO FL; ERPEN L. 2009. Concentração da solução nutritiva no crescimento da planta, na produtividade e na qualidade de frutos do morangueiro. Ciência Rural 39: 684-690.

ANTUNES LEC; RISTOW NC; KROLOW ACR; CARPENEDO S; REISSER JÚNIOR C. 2010. Yield and quality of strawberry cultivars. Horticultura Brasileira 28: 222-226.

BARSAN C; BEL PS; ROMBALDI C; EA I; ROSSIGNOL M; KUNTZ M; ZOUINE M; LATCHÉA; BOUZAYEN M; PECH JC. 2010. Characteristics of the tomato chromoplast revealed by proteomic analysis. Journal of Experimental Botany, 61: 2413-2431.

BORDIGNON JÚNIOR CL. 2008. Análise química de cultivares de morango em diferentes sistemas de cultivo épocas de colheita. Passo Fundo: UPF. 132p. (Dissertação mestrado).

COGO SLP; CHAVES FC; SHIRMER MA; ZAMBIASI RC; NORA L; SILVA JA; ROMBALDI CV. 2011. Low soil water content during growth contributes to preservation of green colour and bioactive compounds of cold-stored broccoli (Brasica oleraceae L.) florets. Postharvest Biology and Technology 60: 158-163.

COMETTI NN; MATIAS GCS; ZONTA E; MARY W; FERNANDES MS. 2008. Efeito da concentração da solução nutritiva no crescimento da alface em cultivo hidropônicosistema NFT. Horticultura Brasileira 26: 252-257.

COOPER AJ. 1973 Rapid crop turn-round is possible with experimental nutrient film technique. Grower 79: 1048-1052.

COSTA E. 2004. Avaliação da produção do morangueiro em sistemas hidropônicos, utilizando casas de vegetação com diferentes niveis tecnológicos. Campinas: UNICAMP, 130p. (Tese doutorado).

DUARTE TS; PEIL RMN; BACCHIS S; STRASSBURGER AS. 2008. Efeito da carga de frutos e concentrações salinas no crescimento do meloeiro cultivado em substrato. Horticultura Brasileira 26: 348-353.

FARIAS CA; SANTOS AM; COLLARES GL. 1998. Produção de mudas de morangueiro (Fragaria $\mathrm{x}$ ananassa Duch) e níveis de irrigação, Pelotas-RS. Revista Brasileira de Agrociência 2: 95-98.

GIMÉNEZ G; ANDRIOLO JL; GODOI R. 2008. Cultivo sem solo do morangueiro. Ciência Rural 38: 273-279.

GRATTAN SR; GRIEVE CM. 1999. Salinitymineral nutrient relations in horticultural crops. Scientia Horticulturae 78: 127-157.

LEES D; FRANCIS FJ. 1972. Standardization of pigment analyses in cranberries. HortScience 7: 83-84.

LI YL. Analisys of greenhouse tomato production in relation to salinity and shoot environment. 2000. Wageningen: Wageningen University. 96p. (Tese doutorado).

MANHITA AC; TEIXEIRA DM; COSTA CT.
2006. Application of sample disruption methods in the extraction of anthocyanins from solid or semi-solid vegetable samples. Journal of Chromatography 1129: 14-20.

MARTINS DS. Produção e qualidade de frutas de diferentes cultivares de morangueiro em sistema de produção de base ecológica. 2010. Pelotas: UFPEL. 81p. (Dissertação mestrado).

MORAES CAG; FURLANI PR. 1999. Cultivo de hortaliças de frutos em hidroponia em ambiente protegido. Informe agropecuário 20: 105-113.

NIEUWHOF M; GARRETSEN F; OEVEREN JC. 1991. Growth analysis of tomato grown under low energy conditions. Netherlands Journal of Agricultural Science 39: 191-196.

RE R; PELLEGRINI N; PROTEGGENTE A; PANNALA A; YANG M; RICE-EVANS C, 1999. Antioxidant activity applying an improved ABTS radical cation decolorization assay. Free Radical Biology and Medicine 26: 1231-1237.

RESENDE JTV; MORALES RGF; FARIA MV; RISSINI ALL; CAMARGO LKP; CAMARGO CK. 2010. Produtividade e teor de sólidos solúveis de frutos de cultivares de morangueiro em ambiente protegido. Horticultura Brasileira 28: 185-189.

SAROOSHI RA; CRESSWELL GC. 1994. Effects of hydroponic solution composition, electrical conductivity and plant spacing on yield and quality of strawberries. Australian Journal of Experimental Agriculture 3: 529535.

SEVERO J; AZEVEDO ML; CHIM J; SCHREINERT RS; SILVA JA; ROMBALDI CV. 2007. Avaliação de compostos fenólicos, antocianinas e poder antioxidante em morangos cv. Aromas e Camarosa. In: CONGRESSO DE INICIAÇÃO CIENTÍFICA DA UFPEL, 16. Anais eletrônicos... Pelotas: UFPEL. Disponível em: http://www.ufpel.tche.br/ cic/2007/cd/pdf/CA/CA_01394.pdf. Acessado em 10 de fevereiro de 2011.

SEVERO J; TIECHER A; CHAVES FC; SILVA JA; ROMBALDI CV. 2010. Gene transcript accumulation associated with physiological and chemical changes during stages of strawberry cv.Camarosa. Food Chemistry 126: 995-1000.

SHANNON MC; GRIEVE CM. 1999. Tolerance of vegetable crops to salinity. Scientia Horticulturae 78: 5-38.

SONNEVELD C; STRAVER N. 1994. Nutrient solution for vegetables and flowers grown in water or substrates. $10^{\text {th }}$ ed. The Netherlands, proefstation voor Tuinbouw onder Glas Te Naaldwijk. 45p. (Series: Voedingsoplossingen Glastuinbouw, n8).

STRASSBURGER AS; PEIL RMN; FONSECA LA; AUMONDE TZ. 2011. Crescimento e produtividade da abobrinha italiana: efeito da concentração ionica da solução nutritiva. Ciências Agrárias 32: 553-564.

VINCI G; BOTRE F; MELE G; RUGGIERI G. 1995. Ascorbic acid in exotic fruits: a liquid chromatographic investigation. Food Chemistry 53: 211-214.

WETTASINGHE M; SHAHIDI F. 1999. Evening primrose meal: a source of natural antioxidants and scavenger of hydrogen peroxide and oxygen-derived free radicals. Food Chemistry 47: 1801-1812. 